\title{
PARTNER SUPPORTIVE DYADIC COPING AND RELATIONSHIP STABILITY AMONG PARENTS OF CHILDREN WITH AUTISM SPECTRUM DISORDER
}

\begin{abstract}
AJANA LÖW
Faculty of Education and Rehabilitation Sciences, University of Zagreb, University Campus Borongaj, Zagreb, Croatia, contact: ajana.low@erf.unizg.hr
\end{abstract}

Received: 22.07.2021.

Accepted: 28.09.2021.

Original research article

UDK: 159.922-055.52:37-053.2-056.36

doi: $10.31299 /$ hrri.57.2.4

\begin{abstract}
Studies involving parents of children with autism spectrum disorder (ASD) have reported negative relationship outcomes for some couples and positive for others, indicating the need to determine the moderators of the link between stress and divorce. This study aims to examine the moderating effect of partner supportive dyadic coping, i.e., interpersonal coping that involves providing comfort, empathy, or practical advice to one's partner, on the association between parental stress and relationship stability among parents of children with $A S D$. The study was conducted on a sample of parents $(N=89)$ who met the criteria of being in a relationship and parenting at least one child diagnosed with ASD. The questionnaire included the Parental Stress Scale, a subscale of the Dyadic Coping Inventory, an item assessing the potential for divorce, and sociodemographic variables. The logistic regression analysis model explained a substantial amount of the variance of relationship stability. Higher probability of having a stable relationship was associated with lower levels of parental stress and higher levels of supportive dyadic coping. Additionally, supportive dyadic coping buffered the negative effect of parental stress: the effect of stress on relationship stability was evident only among participants whose partners showed low supportive dyadic coping. The results indicate that a relationship does not necessarily end in divorce when a couple experiences stressful circumstances, such as raising a child with ASD. The key factor could be supportive dyadic coping that prevents negative effects of stress on relationship maintenance. Support services should aim to enhance supportive dyadic coping skills among parents, and advocate for the fact that both stress and coping are joint processes of partners in a relationship.
\end{abstract}

Keywords: relationship stability, partner supportive dyadic coping, autism spectrum disorder, parental stress, parenting

\section{INTRODUCTION}

Research in the field of autism spectrum disorder (ASD) has largely focused on the diagnosis, causes, and treatment of the disorder. Although researchers have recognised the issues faced by the families of individuals with ASD, very few studies have systematically examined the intimate relationships of parents of children with ASD. Parenting a child with ASD undoubtedly brings additional challenges for families. Research shows that parental stress is particularly high in this population, starting from when the child is diagnosed (e.g., Karst and Van Hecke, 2012). Due to the child's challenging behaviours, parents of children with ASD face daily difficulties that accumulate into a chronic feeling of distress (McGrew and Keys, 2014). Although the impact of chronic stress on relationship stability in the general population is well established (e.g., Randall and Bodenmann, 2009), there is a lack of information on the factors that moderate this association. Previous studies have suggested the potential role of joint coping (Bodenmann and Cina, 2006), however, to date, coping has not been investigated as a moderating factor. This paper will try to overcome these limitations and reduce the gaps in our current knowledge on the subject, as well as propose guidelines for intervention planning.

The probability of relationship dissolution can be predicted by a number of individual variables such as personality traits or deficits in communi- 
cation skills (e.g., Gottman, Coan, Carrere, and Swanson, 1998; Kelly and Conley, 1987), as well as by various relational and macro-level variables such as economic trends (reviewed in Dronkers, Kalmijn, and Wagner, 2006). Since stress can be a cause and/or a consequence of the above-mentioned variables, one might expect it to be related to relationship outcomes (e.g., Catalano and Dooley, 1977). For example, there is a long-term association between external stress and divorce (e.g. Bodenmann and Cina, 2006). Stress affects the relationship through the spillover mechanism, i.e., stress that arises outside the dyad, such as parental or work-related stress, can affect processes within the dyad (e.g. Falconier, Nussbeck, Bodenmann, Schneider, and Bradbury, 2015; Neff and Karney, 2009). Although the spillover mechanism could be both negative and positive, there is growing empirical support (e.g. Zemp, Nussbeck, Cummings, and Bodenmann, 2017) that external stress reduces relationship satisfaction over time primarily through two pathways. Firstly, the spillover mechanism decreases the time partners spend together, which reduces opportunities for positive couple behaviours, such as affection or intimacy with one's partner (Bodenmann, 2005). Secondly, it lowers the capacity for self-regulation, which encourages partners to express negative individual traits (e.g., aggressiveness) and leads to more frequent conflict and negative couple behaviours. In other words, when people, who otherwise have mostly positive relationship interactions, feel stressed, they will show less positive and more negative relationship interactions. These processes affect relationship quality, satisfaction, and, in the long run, stability.

Chronic daily stressors have proven to be particularly destructive to couples (Randall and Bodenmann, 2009). Therefore, couples raising a child with ASD are a very vulnerable group since they face daily parenting difficulties. Parenting difficulties usually arise from the ambiguity of diagnostic criteria, as well as the extent and severity of ASD symptoms (Martinez-Pedraza, 2012). ASD is a complex neurodevelopmental disorder that includes both developmental delays and behaviour problems (Jang, Dixon, Tarbox, and Granpeesheh, 2011). Developmental delays are evident in social communication and often in intellectual functioning, while behaviour problems include tantrums, aggression, stereotypy, self-injury, and sleeping or eating difficulties. Deficits in the child's social communication can cause parents to feel socially stigmatised and worry about the child's adjustment (Martinez-Pedraza, 2012). Behaviour problems present a particular challenge since they are often physically dangerous, for example, self-injury by hitting, pinching, or scratching, leaving parental supervision without permission, or destroying property (Jang et al., 2011). Some of the behaviours, such as repeated and unusual vocalisations, are also demanding because they are socially unacceptable. Due to the nature and frequency of these challenging behaviours, parenting a child with ASD is associated with lower levels of psychological well-being and coping than parenting a child with other developmental disabilities, such as Down syndrome (Abbeduto et al., 2004). Increased parenting stress in the population of parents of children with ASD begins before diagnosis and continues until after the child becomes an adult (e.g., Karst \& Van Hecke, 2012), making it a risk factor for relationship quality deterioration. While parents of typically developing children show an increase in relationship satisfaction once a child reaches adulthood, parents of children with ASD show a decrease in satisfaction at the same point (Hartley, Barker, Seltzer, Greenberg, and Floyd, 2011). In addition, two studies found that a more stressful parenting day in families of children with ASD was associated with fewer positive and more negative marital interactions during the day (Goetz, Rodriguez, and Hartley, 2019; Hartley, Papp, and Bolt, 2018).

Although one might assume that parents of children with ASD face a higher risk of divorce than parents of typically developing children, previous findings regarding relationship stability are mixed (Sim, Cordier, Vaz and Falkmer, 2016). For example, Hartley et al. (2010) and Baeza-Velasco, Michelon, Rattaz, Pernon and Baghdadli (2013) report an increased divorce rate among parents of children with ASD, whereas Freedman, Kalb, Zablotsky and Stuart (2012) found no such difference in a population-based study. Findings from qualitative studies also show that the impact of 
parental stress on relationship dissolution among these couples is complex (e.g. Marciano, Drasgow, and Carlson, 2015). While some parents report poorer couple adjustment, others show positive effects, such as becoming more tolerant and compassionate as partners, or increasing intimacy and becoming closer to their partner (DePappe and Lindsay, 2018). Bush and Price (2021) concluded that, while these studies generally confirm the association between stress and divorce found in the general population, they also show that negative outcomes (both mental health and relationship outcomes) do not occur in all couples, and when they do occur, they are not as severe as often reported or assumed. Positive mental health outcomes often include indicators of family resilience such as family connectedness and closeness (e.g. Bayat, 2007), personal development in the parenting role, and valuing a strong emotional bond with the child (Potter, 2016). In conclusion, Bush and Price (2021) pointed out the need for further research looking at possible moderators of the link between stress and divorce, such as parental well-being, co-parenting, or partner empathy and support. The review also suggests that the topic of intimate relationships of parents of children with developmental disabilities lacks a clear theoretical framework. In this case, the starting point could be a systemic theory, such as the contextual model of family stress (Boss, 2002).

The contextual model of family stress is often applied to family systems facing severe stressors, and it was developed on the basis of Hill's ABC-X Family Stress Model (1958). The model consists of internal and external elements that determine the course of a family/couple stress process and moderate the relationship between stress and outcome, i.e., good or poor adjustment of the family/ couple. When a family experiences a crisis, there are three possible levels of family reorganisation: the same level as before the crisis, a lower level of family functioning than before the crisis, or a higher level of family functioning than before the crisis (Boss, 2002). External elements include resources outside the family that parents use to cope with the crisis, such as health and education systems. Internal elements include family dynamics such as parental and sibling relationships, and are composed of three dimensions: structural, psychological, and philosophical. While the structural dimension refers to family boundaries and roles and the philosophical dimension refers to family values and beliefs, the psychological dimension refers to family perceptions and a mechanism for coping with a stressful event. Although coping has previously been considered an individual process, i.e., the person deals with stressors alone, the Systemic Transactional Model (STM; Bodenmann, 1995) has introduced the concept of dyadic coping, which assumes that both stress and coping are processes shared between partners in a relationship. Dyadic coping is defined as interpersonal coping in which stress signals from one partner are responded to with corresponding stress coping responses from the other partner (Bodenmann, 1995b). STM assumes that the ways in which stressors affect one partner (and consequently the relationship) can be largely moderated by the support of the other partner. For example, if a mother is feeling overwhelmed because she has been dealing with her child's tantrums all morning, it is important for her spouse to show empathy and understanding when he comes home, or to take over things she normally does to help her. Given the definition of a psychological dimension in the model developed by Boss (2002), one might assume that dyadic coping is an important internal psychological element in families with children with ASD. Therefore, the present study uses a combination of the Boss (2002) model and STM to build its conceptual foundation.

The most important positive form of dyadic coping is supportive dyadic coping, i.e., expressing empathy toward one's partner, providing comfort, or giving practical advice. Both in the general population and in the population of parents of children with ASD, positive forms of dyadic coping have proven to be associated with higher relationship satisfaction (García-López, Sarriá, Pozo, and Recio, 2016). However, studies investigating relationship stability in this regard show inconsistent findings. By combining stress levels and frequency of engaging in individual and dyadic coping strategies, Bodenmann and Cina (2006) were able to classify couples into stable-satisfied, stable-distressed, or separated/divorced groups five years later with $62.1 \%$ accuracy. In another study, 
dyadic coping was associated with relationship stability in couples coping with the death of a child (Bergstraesser, Inglin, Hornung and Landolt, 2015). In contrast, Ruffieux, Nussbeck and Bodenmann (2014) showed that dyadic coping had no association with relationship stability 10 years later (they only found an association between coping and relationship satisfaction). Although it could be argued that coping could contribute to stability via higher satisfaction (a full mediation), the causal link was not investigated in these studies. Thus, we cannot rule out the possibility that relationship satisfaction independently influences coping and stability. It should also be noted that all three studies examined coping as a predictor of relationship stability, not as a moderator of the association between stress and relationship stability (Falconier and Kuhn, 2019).

\section{AIM OF THE STUDY}

The topic of intimate relationships of parents of children with ASD has only recently been systematically investigated. In their review of several studies that addressed the topic of relationship satisfaction in these couples, Sim et al. (2016) reported complex associations and inconsistent findings. Although the effect of chronic stress on relationship stability in the general population is well established (e.g. Randall and Bodenmann, 2009), there is a lack of research on the factors that might moderate this association. Researchers have suggested the possible role of the couple dyadic coping; however coping has not been investigated as a moderating factor. The need for further research on possible moderators of the link between stress and divorce also stems from studies of couples raising children with various types of disabilities. While these studies generally confirm the association between stress and divorce found in the general population, they also show that negative outcomes do not occur in all couples. Therefore, this study aims to examine the moderating effect of partner supportive dyadic coping on the association between parental stress and relationship stability in parents of children with ASD.

This paper uses the framework of the contextual model of family stress (Boss, 2002) and the framework of STM (Bodenmann, 1995). According to the contextual model of family stress, the effect of stressors on the outcome, i.e., good or poor adjustment of the family/couple depends on the internal moderator variables. Given the definition of a psychological dimension in Boss (2002) model, it could be assumed that dyadic coping is an important internal psychological moderator in families with children with ASD. Because parents of children with ASD face chronic stressors and the impact of chronic stress on relationship stability in the general population is well established, it is hypothesised that higher parental stress will be associated with lower relationship stability in these couples. Further, according to Boss' contextual model of family stress, it is hypothesised that partner supportive dyadic coping will have a moderating effect on the association between parental stress and relationship stability. More specifically, supportive dyadic coping is expected to buffer the negative effect of stress: the effect of stress on relationship stability will be larger for participants whose partners show less supportive dyadic coping than for participants whose partners show more supportive dyadic coping.

\section{METHODS}

\section{Participants}

This study was conducted using the criteria sampling method. The inclusion criteria were: (1) parents of at least one child diagnosed with ASD and (2) a current intimate relationship and shared household with a partner. The sample included 89 participants who met the criteria. The sociodemographic characteristics of the sample are listed in Table 1 . The average age of the participants was 40 years, and $66.4 \%$ of participants were women. The average relationship length was 13 years. 59.5\% of participants had a college degree (or higher) and $42.7 \%$ were employed full-time. Children diagnosed with ASD were on average 7.5 years old ( $89 \%$ boys). Challenging behaviours were observed sometimes or often among the children of $69.3 \%$ of the sample.

\section{Instruments}

The questionnaire included measures of parental stress, partner supportive dyadic coping, relationship stability, and sociodemographic variables. 
Table 1. Sociodemographic characteristics of the sample $(N=89)$

\begin{tabular}{|c|c|c|c|c|c|}
\hline Characteristic & Category & $\%$ & M (SD) & Min & Max \\
\hline Age (in years) & - & - & $40.02(6.73)$ & 28 & 62 \\
\hline \multirow[t]{2}{*}{ Gender } & Female & 66.4 & \multirow[t]{2}{*}{ - } & \multirow[t]{2}{*}{-} & \multirow[t]{2}{*}{-} \\
\hline & Male & 33.6 & & & \\
\hline Relationship length (in years) & - & - & $13.25(6.86)$ & 3 & 33 \\
\hline \multirow[t]{3}{*}{ Education level } & Elementary school & 2.2 & \multirow[t]{3}{*}{ - } & \multirow[t]{3}{*}{-} & \multirow[t]{3}{*}{-} \\
\hline & High school & 38.2 & & & \\
\hline & College or higher & 59.5 & & & \\
\hline \multirow[t]{4}{*}{ Employment } & Full-time & 42.7 & \multirow[t]{4}{*}{-} & \multirow[t]{4}{*}{-} & \multirow[t]{4}{*}{-} \\
\hline & Part-time & 19.1 & & & \\
\hline & $\begin{array}{l}\text { Maternity leave or parent } \\
\text { caregiver status }\end{array}$ & 17.9 & & & \\
\hline & Unemployed & 25.8 & & & \\
\hline \multirow[t]{3}{*}{ Household income } & Below averag & 25.8 & \multirow[t]{3}{*}{ - } & \multirow[t]{3}{*}{-} & \multirow[t]{3}{*}{ - } \\
\hline & Average & 47.2 & & & \\
\hline & Above average & 27.0 & & & \\
\hline Number of children & - & - & $1.94(0.92)$ & 1 & 5 \\
\hline Age of child with ASD & - & - & $7.50(3.38)$ & 4.0 & 16.6 \\
\hline \multirow[t]{2}{*}{ Gender of child with ASD } & Female & 11 & \multirow[t]{2}{*}{-} & \multirow[t]{2}{*}{ - } & \multirow[t]{2}{*}{-} \\
\hline & Male & 89 & & & \\
\hline \multirow[t]{4}{*}{ Challenging behaviours } & Never & 3.4 & \multirow[t]{4}{*}{ - } & \multirow[t]{4}{*}{-} & \multirow[t]{4}{*}{-} \\
\hline & Rare & 18.2 & & & \\
\hline & Sometimes or often & 69.3 & & & \\
\hline & Very often & 9.1 & & & \\
\hline
\end{tabular}

$A S D$, autism spectrum disorder; $M$, mean; Max, maximum observed value; $M i n$, minimum observed value; $S D$, standard deviation

The Parental Stress Scale (Berry and Jones, 1995) measures the level of parental stress and includes both positive (e.g., emotional benefits) and negative (e.g., demands on resources) aspects of parenting. The scale includes 18 questions that require responses with a Likert-type level of agreement from 1 ("strongly disagree") to 5 ("strongly agree"). An example item is "Having a child leaves little time and flexibility in my life". A low score indicates a low level of stress. The scale was previously validated on a Croatian sample (Milić Babić and Laklija, 2013). In the present study, the internal consistency of the scale was $\alpha=.89$.

Partner supportive dyadic coping is a subscale of the Dyadic Coping Inventory (DCI; Bodenmann, 2008), and it measures perceptions of partner supportive dyadic coping, the provision of problem-focused and/or emotion-focused support to help the partner cope when one or both partners are stressed. The subscale includes five items rated on a scale, where 1 indicates "very rarely" and 5 indicates "very often". An example item is "(When I feel stressed) my partner shows empathy and understanding for me". A low score indicates a low level of supportive dyadic coping. The scale has cut-off values with respect to dyadic coping (Bodenmann, 2008): $<3.17=$ below average; $3.17-4.14=$ within normal range; $>4.14=$ above average. The scale was previously validated on a Croatian sample (Alimović et al., 2016). In the present study, the internal consistency of the scale was $\alpha=.94$.

Relationship stability was measured using a single item assessing the couple's potential for separation or divorce - "Have you seriously considered break-up/divorce in the past year?" with responses of "yes" or "no." Responses were later coded into a dummy variable $(0=$ "unstable couple", $1=$ "stable couple"). A similar single-item approach is common in relationship stability research (e.g. Barton and Bryant, 2016; Johnson and Anderson, 2013). Sociodemographic variables were developed for the purpose of the study and included data on the participants (age, gender, education level, relationship duration, employment, and monthly income) 
and data on the child with ASD (age, gender, and frequency of challenging behaviours).

\section{Procedures}

All data were collected in the spring of 2019. Participants were recruited through cooperation with kindergartens, primary schools, and the centre for autism in the city of Zagreb. The study was conducted in accordance with the Code of Ethics of the Ethics Committee in Science and Higher Education in Croatia, the Code of Ethics of the University of Zagreb, and the Rules of Procedure of the Ethics Committee of the Faculty of Education and Rehabilitation Sciences (Approval of the Ethics Committee of the Faculty of Education and Rehabilitation Sciences). Questionnaires were distributed by special education teachers, who gave the parents an informed letter, consent form, and the questionnaire. The questionnaires were returned in sealed envelopes to protect the identity of the participants. All analyses were done using SPSS (version 23). Descriptive statistics and correlations with bootstrapping were used for the initial analyses. Hierarchical binary logistic regression analysis was performed to further explore the relationships between variables. A model with parental stress as a predictor, partner supportive dyadic coping as a moderator, and relationship stability as a criterion variable was tested. To obtain the moderator variable, a multiplication of the standardised variables of parental stress and supportive dyadic coping was used.

\section{RESULTS}

Descriptive statistics and correlations between variables are listed in Table 2. Based on the frequencies of the relationship stability dummy variable, $57.5 \%$ of the sample were categorised as stable couples, while $42.5 \%$ were unstable couples.
Descriptive statistics for parental stress indicate that, on average, participants reported moderate levels of parental stress that varied widely across participants. The mean and standard deviation for partner supportive dyadic coping indicate that, on average, participants reported moderate levels of partner supportive dyadic coping that varied widely between participants. Looking at the cut-off scores for the DCI, $22.7 \%$ of participants reported a below average level of dyadic coping, $46.6 \%$ of participants reported a dyadic coping level in the normal range, and $30.7 \%$ of participants reported a dyadic coping level above average.

To address the categorical nature of the criterion variable, correlations between variables were calculated using the point-biserial correlation coefficient with bootstrapping (Table 2). Firstly, correlation analyses were conducted between the criterion variable and sociodemographic variables (at both the parent and child levels). None of the control variables were significantly associated with criterion, so they were not included in the regression analysis. Secondly, correlation analyses were conducted between the criterion variable and the predictor variables. As expected, the results showed that the correlation coefficient between the predictor variables, i.e., parental stress and partner supportive dyadic coping, was not significant. Consistent with the hypotheses, both predictor variables were significantly associated with the criterion variable, relationship stability. Higher levels of parental stress were associated with lower relationship stability $(r=-.29 ; \mathrm{p}<.01)$, whereas higher levels of partner supportive dyadic coping were associated with higher relationship stability $(\mathrm{r}=.41 ; \mathrm{p}<.01)$.

Next, the assumptions for binary logistic regression analysis were checked. Binary logistic regression requires a minimum of 10 events per predictor variable (Peduzzi, Concato, Kemper,

Table 2. Descriptive statistics and point-biserial correlation coefficient with bootstrapping between variables $(N=89)$

\begin{tabular}{|l|l|c|c|c|c|c|c|c|}
\hline Variable & & $\mathbf{0}$ & M (SD) & Min & Max & $\mathbf{1}$ & $\mathbf{2}$ & $\mathbf{3}$ \\
\hline 1. Parental stress & & - & $41.17(10.76)$ & 18 & 90 & - & -.21 & $-.29^{* *}$ \\
\hline 2. Supportive dyadic coping & & - & $3.66(1.00)$ & 1 & 5 & & - & $.41^{* *}$ \\
\hline \multirow{2}{*}{ 3. Relationship stability } & Stable & 57.5 & - & - & - & & \\
\cline { 2 - 9 } & Unstable & 42.5 & & & & & \\
\hline
\end{tabular}

M, mean; Max, theoretical maximum value; Min, theoretical minimum value; SD, standard deviation; **, $p<.01$ 
Hrvatska revija za rehabilitacijska istraživanja 2021, Vol 57, br. 2, str. 59-72

Table 3. Final step of the hierarchical binary logistic regression analysis explaining relationship stability $(N=89)$

\begin{tabular}{|l|c|c|c|c|c|}
\hline Predictor & B (S.E.) & Wald & OR & $\chi^{2}$ (df) & R2 \\
\hline Parental stress & $-0.648(0.287)$ & $5.075^{*}$ & 0.523 & & \\
\hline Supportive dyadic coping & $1.291(0.369)$ & $12.263^{* *}$ & 3.637 & & \\
\hline Moderator & $-0.533(0.227)$ & $5.481^{*}$ & 0.587 & & \\
\hline Test & & & & $24.889(3)^{* *}$ & \\
\hline Overall model evaluation & & & $8.070(8)$ & .354 \\
\hline Hosmer \& Lemeshow test & & & &. \\
\hline Nagelkerke & & & & \\
\hline
\end{tabular}

$B$, unstandardized regression coefficient; $d f$, degrees of freedom; $O R$, odds ratio; $R^{2}$, coefficient of determination; S.E., standard error of the estimate; Wald, chi-square test statistic for the individual predictor variable; $\chi^{2}$, chi-square; ${ }^{* *}, p<.01 ;{ }^{*}, p<.05$

Holford and Feinstein, 1996); some authors provide evidence for a looser cut-off point (Vittinghoff and McCulloch, 2007). This means that the smaller category of the outcome variable should be at least 10 times the number of predictor variables. Considering that the number of participants in the unstable couples group (which is the smaller of the two categories of the outcome variable in this study) was 37 , this assumption was met. Further, logistic regression requires no multicollinearity between predictor variables, so collinearity statistics were performed. The variance inflation factor values were below the cut-off point of five, indicating the assumption was met. Logistic regression also requires linearity of the predictor variables and log odds, so a Box-Tidwell procedure was performed, which requires the interaction between the predictor and the natural $\log$ of the predictor to be added to the model (Osborne, 2015). The interactions were not significant, indicating this assumption was also met.

To test the hypotheses, a hierarchical binary logistic regression analysis was conducted with relationship stability as the criterion variable. In the first step, the variables parental stress and partner supportive dyadic coping were entered. In the second step, the moderator variable, i.e., the interaction between parental stress and supportive dyadic coping was introduced. The first block of variables explained a statistically significant proportion of the variance of the criterion variable $\left(\chi^{2}(2)=19.896, \mathrm{p}<.01\right.$; Nagelkerke $\left.\mathrm{R}^{2}=.291\right)$. The Hosmer-Lemeshow test was not significant $(p>.05)$, indicating that the model fits the data well. When the moderator variable was introduced in the second step, the percentage of variance explained increased significantly by $6.3 \%$.
The final model explained a statistically significant proportion of the variance of the criterion variable $\left(\chi^{2}(3)=24.889, p<.01\right.$; Nagelkerke $\left.R^{2}=.354\right)$. The Hosmer-Lemeshow test was not significant ( $\mathrm{p}$ $>.05$ ), indicating that the model fits the data well. The results of the final step of the hierarchical binary logistic regression analysis are provided in Table 3.

The final model correctly classified $69.5 \%$ of participants. Higher probability of having a stable relationship was associated with lower scores on parental stress and higher scores on partner supportive dyadic coping. For each point increase in parental stress, the odds of being in a stable relationship decreased by $47.7 \%[\operatorname{Exp}(\mathrm{B})=0.523$, $95 \%$ CI $(0.298,0.919)]$. When parental stress was held constant, for each point increase in partner supportive dyadic coping, the odds of being in a stable relationship increased almost threefold [Exp (B) $=3.637,95 \%$ CI $(1.766,7.492)]$.

The moderating effect of partner supportive dyadic coping on the association between parental stress and relationship stability is shown in Figure 1. Using Dawson's procedure (2014), simple slope tests, i.e., conditional hypothesis tests of whether the association between predictor variables and a criterion variable is significant at a given value of the moderator were plotted. According to the recommendations, theoretically meaningful values were chosen: the values were set at 0 and 4.14, which corresponds to the DCI cut-off value for above-average dyadic coping.

As evident from Figure 1, partner supportive dyadic coping buffered the negative effect of parental stress. In other words, the effect of stress on relationship stability was evident only among 

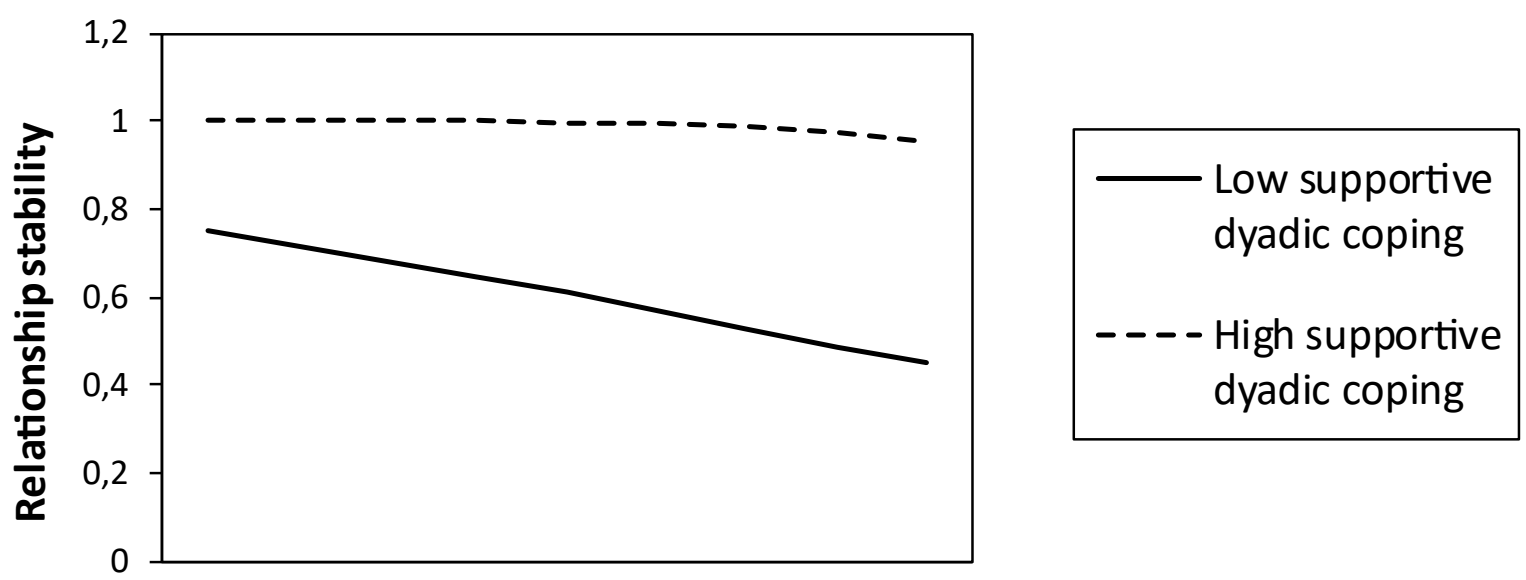

Low Parental stress

High Parental stress

Figure 1. Moderating effect of partner supportive dyadic coping on the association between parental stress and relationship stability $(N=89)$

participants whose partners showed low supportive dyadic coping, whereas there was no such effect among participants whose partners showed high supportive dyadic coping.

\section{DISCUSSION}

Despite elevated levels of stress among parents of children with ASD, research findings regarding relationship stability in this population are mixed, showing negative outcomes for some couples and positive outcomes for others (e.g. Sim et al., 2016). Therefore, researchers suggest the need for further investigation of the potential moderators of the link between stress and divorce. This study aimed to examine one such moderator, partner supportive dyadic coping, which is a variable that has been investigated as a predictor of relationship stability in the general population, but has not yielded conclusive results. Using the framework of the contextual model of family stress (Boss, 2002), it was hypothesised that higher parental stress would be associated with lower relationship stability, and that partner supportive dyadic coping would have a moderating effect on the association between parental stress and relationship stability.

The results of this study confirmed the first hypothesis: parental stress negatively correlated with relationship stability. A higher probability of having a stable relationship was associated with lower levels of parental stress. For each point increase in parental stress, the odds of being in a stable relationship decreased by $47.7 \%$. These findings are consistent with research showing a long-term association between external stress and relationship dissolution (e.g. Bodenmann and Cina, 2006). Stress that originates outside the couple itself, such as parental stress, can influence processes within the couple through the spillover mechanism (e.g. Falconier et al., 2015; Neff and Karney, 2009). This mechanism typically involves: (1) a decrease in the time partners spend together, which reduces opportunities for positive couple behaviours, and (2) a decrease in the capacity for self-regulation, which leads to more frequent conflict and negative couple behaviours. Therefore, couples engage in fewer positive and more negative relationship interactions, which can affect relationship quality and may lead to a break-up in the long run.

It should be noted that, on average, study participants reported only moderate levels of parental stress. This finding seems somewhat surprising since parents of children with ASD typically show elevated stress levels, likely due to the number and intensity of the child's difficulties, particularly challenging behaviours that are often dangerous to the child or socially unacceptable (e.g. self-injuring, leaving the parent's supervision, repeated/ unusual vocalisations, destruction of property) (McGrew and Keys, 2014). This finding could 
have two possible explanations. Firstly, the sampling procedure in this study was non-probabilistic, which is evident from the sample description. The educational level of our participants is above average, therefore, it could be assumed that they have above average resources for coping with stress, such as high professional support, better knowledge of the diagnosis, better knowledge of coping mechanisms, and better communication skills. Secondly, the measure of parental stress used includes the items that measure the construct of parental stress, but also some aspects of a broader construct of parenting in general (for example, "I enjoy spending time with my child"). Therefore, the construct of parental stress might be only partially captured. It is also questionable whether the instrument can measure stress that is specifically associated with families with a child with ASD (e.g., coping with day-to-day parenting hassles or dealing with challenging behaviours). This may also account for the fact that study participants reported only moderate levels of parental stress.

The second hypothesis of this study, which corresponds to the contextual model of family stress developed by Boss (2002), was that partner supportive dyadic coping would have a moderating effect on the association between parental stress and relationship stability. Specifically, it was hypothesised that stress would have a greater effect on relationship stability among participants whose partners showed less supportive dyadic coping than for participants whose partners showed more supportive dyadic coping. The results of the study confirmed this hypothesis: partner supportive dyadic coping buffered the negative effect of parental stress. The effect of stress on relationship stability was only evident in participants whose partners show low supportive dyadic coping, whereas there was no such effect in participants whose partners show high supportive dyadic coping. This could be illustrated by the example of a mother who feels overwhelmed with her child's challenging behaviour throughout the day. The results of this study indicate that if this woman's partner shows empathy and understanding towards her or if he takes over the things she normally does in order to help her, her feelings of stress would have no effect on relationship stability. On the other hand, if this woman's partner does not show empathy and understanding towards her, or if he does not want to take on the things she normally does, her feelings of stress would have an impact on relationship stability.

This result corresponds to Boss's contextual model of family stress (2002), which assumes that different elements moderate the association between stress and outcome, such as a family/ couple crisis or family/couple adjustment. It is also consistent with the STM (Bodenmann, 1995), which assumes that both stress and coping are processes shared between partners in a relationship, and that the way in which stressors affect one partner (and consequently the relationship) could be largely moderated by the support of the other partner. Although positive forms of dyadic coping have proven to be associated with higher relationship satisfaction, studies that tried to link positive dyadic coping to relationship stability showed mixed results (Bodenmann and Cina, 2006; Ruffieux et al., 2014). It should also be noted that the possible moderating effect of coping on the association between stress and stability has not yet been investigated. In addition, previous studies did not include parents of children with ASD or parents of children with any other type of disability. Therefore, to the best of knowledge, this is the first study to examine dyadic coping as a moderating variable of the link between stress and relationship stability among parents of children with disabilities.

The results of this study suggest that a relationship does not necessarily have to end in divorce when a couple goes through stressful circumstances such as raising a child with ASD. This is further evidenced by the fact that $57.5 \%$ of the sample were categorised as "stable couples", while $42.5 \%$ were categorised as "unstable couples". Other studies have confirmed these results: while Hartley et al. (2010) and Baeza-Velasco et al. (2013) reported an increase in the divorce rate among parents of children with ASD, a population-based study reported no such differences (Freedman et al., 2012). Further, findings from qualitative studies show that the impact of parental stress on relationship dissolution among these couples is complex (e.g. Marciano et al., 2015). Most importantly, the key variable that distinguishes stable and unstable 
couples in this study is supportive dyadic coping. Higher probability of having a stable relationship was associated with higher levels of partner supportive dyadic coping. Parental stress held constant, for every point increase in partner supportive dyadic coping, the odds of being in a stable relationship increased almost threefold. Moreover, partner supportive dyadic coping buffered the negative effect of parental stress, indicating that even though coping may not reduce stress itself, it could prevent its negative effects on relationship maintenance.

The results of this study must be considered with caution in the light of several limitations. The sampling method was non-probabilistic resulting in a sample that was not representative of the population, both in terms of gender and education. To obtain stronger conclusions, the same variables could also be studied using a sample of parents raising children without developmental delays. Future research should therefore be conducted on a representative sample of parents of children with ASD, as well as a comparative sample of parents of typically developing children. In addition, this study did not include both parents of a couple (only one parent), so the advanced dyadic analyses could not be conducted. Secondly, this study is cross-sectional and it is not possible to draw conclusions about causal relationships between variables. For example, an unstable relationship could lead to increased parental stress as well. Therefore, longitudinal studies that allow causal inferences should be planned. Thirdly, the instruments used in this study could be improved. The measure of stress, as mentioned earlier, lacks a grounded concept of stress specific to parents of children with ASD. The measure of relationship stability, although indicating a likelihood of divorce, does not provide information on whether these couples would actually separate at some point. Moreover, the relatively high number of parents who were classified as "unstable couples" based on this indicator should be considered with caution. Indeed, the response of these couples could also reflect the current situation of conflict or increased stress, which could be temporary. Therefore, it might be beneficial for future research to have both married and divorced participants in the sample, and to use more sophisticated methods such as the diary meth- od. Finally, this study did not account for other potential moderators such as work engagement or household labour division, which have proved to be important variables in studies of intimate relationships in the general population (e.g. Author A, 2016). In addition, future studies should control for other variables related to the child with ASD, such as severity of symptoms in social and cognitive functioning, as well as problems associated with the parent-child relationship.

\section{CONCLUSIONS AND RECOMMENDATIONS}

To the best of knowledge, this is the first study to examine dyadic coping as a moderator of the link between stress and relationship stability in parents of children with disabilities. The findings support Boss's contextual model of family stress (2002), which posits that different elements in the family's life could influence the association between stress and the outcome for the family, i.e., a crisis or adjustment. In this study, partner supportive dyadic coping buffered the negative effect of parental stress: the effect of stress on relationship stability was evident only when partners showed low supportive dyadic coping, whereas there was no such effect when partners showed high supportive dyadic coping. In conclusion, the results suggest that a relationship does not necessarily have to end in divorce when a couple is experiencing stressful circumstances, such as raising a child with ASD. The key variable that distinguishes stable and unstable couples is supportive dyadic coping. Although coping may not reduce stress itself, it could prevent its negative effects on maintaining the relationship.

The findings of this study are important for planning support services for families raising a child with ASD. Most programs for parents focus on knowledge and information about ASD, as well as on developing parenting skills and managing challenging behaviours (Preece and Trajkovski, 2017). This study suggests that such programmes should also include strengthening parents' intimate relationships. It is critical to enhance skills of supportive dyadic coping, an interpersonal coping that involves expressing empathy toward one's partner, providing comfort, or giving practical advice. 
Given that a substantial proportion of the sample in this study reported below-average levels of dyadic coping, and taking into account that they were above-average educated individuals, the importance of including these topics in support services is very important, particularly among vulnerable couples (e.g., minimal educational qualifications or low-income couples). Programs should also promote that both stress and coping are not just individual processes, i.e., the person deals with the stressors alone, but also joint processes shared by partners in a relationship.

\section{ACKNOWLEDGEMENTS}

Special thanks to the parents who participated in this study

Funding: This research study received no specific grant from any funding agency in the public, commercial, or not-for-profit sectors.

The author(s) declare no relevant financial or non-financial competing interests. 


\section{REFERENCES}

Abbeduto, L., Seltzer, M. M., Shattuck, P., Krauss, M. W., Orsmond, G., \& Murphy, M. M. (2004). Pychological wellbeing and coping in mothers of youths with autism, Down syndrome, or fragile X syndrome. American Journal of Mental Retardation, 109(3), 237-254. doi: 10.1352/0895-8017(2004)109.

Alimović, S., Lisak, N., Cvitković, D., Wagner Jakab, A., Žic Ralić, A., \& Stošić, J. (2016). Socijalna inkluzija i dobrobit obitelji djece s teškoćama: Nacionalno izvješće Hrvatska [Social inclusion and the welfare of families of children with disabilities: National report Croatia]. Edukacijsko-rehabilitacijski fakultet Sveučilišta u Zagrebu.

Author A. (2016). [Title and other information omitted for blind review].

Baeza-Velasco, C., Michelon, C., Rattaz, C., Pernon, E., \& Baghdadli, A. (2013). Separation of parents raising children with autism spectrum disorders. Journal of Developmental and Physical Disabilities, 25(6), 613-624. doi: $10.1007 / \mathrm{s} 10882-013-9338-0$

Barton, A. W., \& Bryant, C. M. (2016). Financial strain, trajectories of marital processes, and African American newlyweds' marital instability. Journal of Family Psychology, 30(6), 657. doi: 10.1037/fam0000190

Bayat, M. (2007). Evidence of resilience in families of children with autism. Journal of Intellectual Disability Research, 51, 702-714. doi: 10.1111/J.1365-2788.2007.00960.X

Bergstraesser, E., Inglin, S., Hornung, R., \& Landolt, M. A. (2015). Dyadic coping of parents after the death of a child. Death studies, 39(3), 128-138. doi: 10.1080/07481187.2014.920434

Berry, J. O., \& Jones, W. H. (1995). The parental stress scale: Initial psychometric evidence. Journal of Social and Personal Relationships, 12(3), 463-472. doi: 10.1177/0265407595123009.

Bodenmann, G. (1995a). A systemic-transactional conceptualization of stress and coping in couples. Swiss Journal of Psychology, 54(1), 34-49.

Bodenmann, G. (1995b). Dyadische Coping und Partnerschaftszufriedenheit [Dyadic coping and marital satisfaction]. Psychologische Beiträge, 37, 72-89.

Bodenmann, G. (2005). Dyadic coping and its significance for marital functioning. In T. Revenson, K. Kayser, \& G. Bodenmann (Eds.), Couples coping with stress: Emerging perspectives on dyadic coping (pp. 33-50). Washington, DC: American Psychological Association

Bodenmann, G. (2008). Dyadisches Coping Inventar: Test manual [Dyadic Coping Inventory: Test manual]. Bern, Switzerland: Huber.

Bodenmann, G., \& Cina, A. (2006). Stress and coping among stable-satisfied, stable-distressed and separated/divorced Swiss couples: A 5-year prospective longitudinal study. Journal of Divorce \& Remarriage, 44(1-2), 71-89. doi: 10.1300/J087v44n01_04

Boss, P. (2002). Family stress management, 2nd ed. Newbury Park, CA: Sage.

Bush, K. R., \& Price, C. A. (Eds.). (2021). Families \& change: Coping with stressful events and transitions (6 $6^{\text {th }}$ Edition). Sage.

Catalano, R., \& Dooley, C. D. (1977). Economic predictors of depressed mood and stressful life events in a metropolitan community. Journal of Health and Social Behavior, 18(3), 292-307. doi: 10.2307/2136355.

Dawson, J. F. (2014). Moderation in management research: What, why, when and how. Journal of Business and Psychology, 29, 1-19.

DePape, A. M., \& Lindsay, S. (2015). Parents' experiences of caring for a child with autism spectrum disorder. Qualitative health research, 25(4), 569-583. doi: 10.1177/1049732314552455

Dronkers, J., Kalmijn, M., \& Wagner, M. (2006). Causes and consequences of divorce: Cross-national and cohort differences, an introduction to this special issue. European Sociological Review, 22(5), 479-481. doi: 10.1093/ esr/jcl015 
Falconier, M. K., \& Kuhn, R. (2019). Dyadic coping in couples: A conceptual integration and a review of the empirical literature. Frontiers in Psychology, 10, 571. doi: 10.3389/fpsyg.2019.00571.

Falconier, M. K., Nussbeck, F., Bodenmann, G., Schneider, H., \& Bradbury, T. (2015). Stress from daily hassles in couples: Its effects on intradyadic stress, relationship satisfaction, and physical and psychological wellbeing. Journal of Marital and Family Therapy, 41(2), 221-235. doi: 10.1111/jmft.12073

Freedman, B. H., Kalb, L. G., Zablotsky, B., \& Stuart, E. A. (2012). Relationship status among parents of children with autism spectrum disorders: A population-based study. Journal of autism and developmental disorders, 42(4), 539-548. doi: 10.1007/s10803-011-1269-y

García-López, C., Sarriá, E., Pozo, P., \& Recio, P. (2016). Supportive dyadic coping and psychological adaptation in couples parenting children with autism spectrum disorder: The role of relationship satisfaction. Journal of Autism and Developmental Disorders, 46(11), 3434-3447. doi: 10.1007/s10803-016-2883-5.

Goetz, G. L., Rodriguez, G., \& Hartley, S. L. (2019). Actor-partner examination of daily parenting stress and couple interactions in the context of child autism. Journal of Family Psychology, 33(5), 554-564. doi: 10.1037/fam0000527

Gottman, J. M., Coan, J., Carrere, S., \& Swanson, C. (1998). Predicting marital happiness and stability from newlywed interactions. Journal of Marriage and the Family, 5-22. doi: 10.2307/353438

Hartley, S. L., Barker, E. T., Seltzer, M. M., Floyd, F., Greenberg, J., Orsmond, G., \& Bolt, D. (2010). The relative risk and timing of divorce in families of children with an autism spectrum disorder. Journal of Family Psychology, 24(4), 449. doi: 10.1037/a0019847

Hartley, S. L., Barker, E. T., Seltzer, M. M., Greenberg, J. S., \& Floyd, F. J. (2011). Marital satisfaction and parenting experiences of mothers and fathers of adolescents and adults with autism. American Journal of Intellectual and Developmental Disabilities, 116(1), 81-95. doi: 10.1352/1944-7558-116.1.81

Hartley, S. L., Papp, L. M., \& Bolt, D. (2018). Spillover of marital interactions and parenting stress in families of children with autism spectrum disorder. Journal of Clinical Child \& Adolescent Psychology, 47(sup1), S88-S99. doi: $10.1080 / 15374416.2016 .1152552$.

Hill, R. (1958). Generic Features of Families under Stress. Social casework, 39(2-3), 139-150. doi: $10.1177 / 1044389458039002-318$.

Jang, J., Dixon, D. R., Tarbox, J., \& Granpeesheh, D. (2011). Symptom severity and challenging behaviour in children with ASD. Research in Autism Spectrum Disorders, 5(3), 1028-1032. doi: 10.1016/j.rasd.2010.11.008

Johnson, M. D., \& Anderson, J. R. (2013). The longitudinal association of marital confidence, time spent together, and marital satisfaction. Family process, 52(2), 244-256. doi: 10.1111/j.1545-5300.2012.01417.x

Karst, J. S., \& Van Hecke, A. V. (2012). Parent and family impact of autism spectrum disorders: A review and proposed model for intervention evaluation. Clinical Child and Family Psychology Review, 15(3), 247-277. doi: 10.1007/ s10567-012-0119-6

Kelly, E. L., \& Conley, J. J. (1987). Personality and compatibility: a prospective analysis of marital stability and marital satisfaction. Journal of personality and social psychology, 52(1), 27. doi: 10.1037/0022-3514.52.1.27

Marciano, S. T., Drasgow, E., \& Carlson, R. G. (2015). The marital experiences of couples who include a child with autism. The Family Journal, 23(2), 132-140. doi: 10.1177/1066480714564315

Martínez-Pedraza, F. D. L. (2012). Parental well-being within the marital subsystem: A study of mother-father dyads raising young children with Autism. University of Massachusetts Boston.

McGrew, J. H., \& Keys, M. L. (2014). Caregiver stress during the first year after diagnosis of an autism spectrum disorder. Research in Autism Spectrum Disorders, 8(10), 1373-1385. doi: 10.1016/j.rasd.2014.07.011

Milić Babić, M., \& Laklija. M. (2013). Strategije suočavanja roditelja djece s teškoćama u razvoju predškolske dobi [Coping strategies in parents of preschool children with disabilities]. Socijalna psihijatrija, 41(4), 215-225. 
Neff, L. A., \& Karney, B. R. (2009). Stress and reactivity to daily relationship experiences: How stress hinders adaptive processes in marriage. Journal of Personality and Social Psychology, 97(3), 435-450. doi: 10.1037/a0015663

Osborne, J. (2015). A practical guide to testing assumptions and cleaning data for logistic regression. In Best practices in logistic regression (pp. 84-130). Sage Publications. doi: 10.4135/9781483399041

Peduzzi, P., Concato, J., Kemper, E., Holford, T. R., \& Feinstein, A. R. (1996). A simulation study of the number of events per variable in logistic regression analysis. Journal of clinical epidemiology, 49(12), 1373-1379. doi: $10.1016 / \mathrm{s} 0895-4356(96) 00236-3$

Preece, D. \& Trajkovski, V. (2017). Parent education in autism spectrum disorder - a review of the literature. Hrvatska revija za rehabilitacijska istraživanja, 53 (1), 128-138. https://doi.org/10.31299/hrri.53.1.10

Potter, C. A. (2016). 'I accept my son for who he is-he has incredible character and personality': fathers' positive experiences of parenting children with autism. Disability \& Society, 31(7), 948-965. doi: 10.1080/09687599.2016.1216393.

Randall, A. K., \& Bodenmann, G. (2009). The role of stress on close relationships and marital satisfaction. Clinical Psychology Review, 29(2), 105-115. doi: 10.1016/j.cpr.2008.10.004

Ruffieux, M., Nussbeck, F. W., \& Bodenmann, G. (2014). Long-term prediction of relationship satisfaction and stability by stress, coping, communication, and well-being. Journal of Divorce \& Remarriage, 55(6), 485-501. doi: $10.1080 / 10502556.2014 .931767$

Sim, A., Cordier, R., Vaz, S., \& Falkmer, T. (2016). Relationship satisfaction in couples raising a child with autism spectrum disorder: A systematic review of the literature. Research in Autism Spectrum Disorders, 31, 30-52. doi: 10.1016/j.rasd.2016.07.004

Vittinghoff, E. \& McCulloch, C. E. (2007). Relaxing the Rule of Ten Events per Variable in Logistic and Cox Regression. American Journal of Epidemiology, 165(6), 710-718. doi: 10.1093/aje/kwk052

Zemp, M., Nussbeck, F. W., Cummings, E. M., \& Bodenmann, G. (2017). The spillover of child-related stress into parents' relationship mediated by couple communication. Family Relations, 66(2), 317-330. doi: 10.1111/fare.12244 